\title{
A MODIFIED COMPUTATIONAL APPROACH BASED ON KANE'S METHOD
}

\author{
Bilal Maher \\ Basic Eng. Sciences Dept. \\ Faculty of Engineering \\ Menoufia University \\ Shebin El-Kom, EGYPT
}

\author{
Salem Samak \\ Prod. Eng. and Mech. Design Dept. \\ Faculty of Engineering \\ Menoufia University \\ Shebin El-Kom, EGYPT
}

\begin{abstract}
The partial angular velocities and partial linear velocities play a fundamental role in forming Kane's equations of motion. The objective of this paper is to develop an improved computational approach in order to simplify and solve Kane's equations of motion for multibody systems. This can be achieved by obtaining an optimal set of generalized speeds which are first randomly selected. They could be chosen as a set of angular velocities and linear velocities or simply a set of independent joint velocities. The proposed method has shown that Kane's method can be modified and leads to an optimal set, of generalized speeds, which leads to simpler equations of motion. An application is adopted to illustrate the proposed approach.
\end{abstract}

\section{KEYWORDS}

Kane's Method, Multibody System Dynamics, Robotics.

\section{INTRODUCTION}

During recent years, there have been many attempts to develop efficient formulations for deriving equations of motion for multibody systems, especially for open-chain systems [1,2]. Most of these attempts [3-8] have been motivated by advances in computer hardware and software as well as in computational methods used to derive the equations of motion of multi-body systems. Most

Manuscript received from Dr. SALEM SAMAK

on : $6 / 9 / 2000$

Accepted on : $28 / 9 / 2000$

Engineering Research Bulletin, Vol 23,No 4, 2000 Minufiya University, Faculty of Engineering, Shebien El-Kom, Egypt, ISSN 1110-1180 
writers and researchers have formulated these equations utilizing either Newton's laws, Lagrange's equations or some modified geometrical theory. Each of these approaches, however, has the objective of efficient development of computer-oriented equations. The relative advantages and disadvantages of these approaches depend on the particular dynamic method used and the method of organizing the geometry.

Kane's method for formulating the dynamic equations of motion [9-13], which is attributed to T. R. Kane, is a recently developed principle gaining increasing recognition, particularly in its applications with multibody systems. This method is developed in the early 1960's. It was originally called "Lagrange's form of d'Alembert's principle". In recent years, the procedure based on this principle is referred to as "Kane's Equations". Kane's method is stated as a fundamental proposition. It is utilized as a starting point for the development of various other methods of formulating equations of motion.

These equations provide an automatic elimination of the non-working internal constraint forces without the introduction of tedious differentiations. This reduces the work needed to formulate the equations of motion and also yields simple equations. Huston et al. [14] have developed combined methods for Kane's equations with geometric and computational procedures. Utilizing these methods, general multibody systems can be analyzed in general external force fields. Moreover, the internal forces between the bodies are allowed to be either specified or unknown.

The paper presents a new improved computational method for Kane's formulation to simplify and solve the equations of motion of spatial multibody systems. In a dynamic system, the linear velocities and angular velocities are linear functions of the generalized coordinate derivatives. The coefficients of these derivatives are called partial velocities and partial angular velocities. The scalar components of partial velocities and partial angular velocities play a fundamental role in forming the coefficients of the governing equations of motion. It is often convenient to introduce and define coordinate derivatives that are linear combinations of other coordinate derivatives, such combinations are known as generalized speeds. The generalized speeds in Kane's method play a fundamental role in forming the governing equations of motion. They are quantities intimately associated with the system motion, rather than merely with its configuration. They also serve as dependent variables on an equal footing with the generalized coordinates. Their introduction can enable one to take advantage of special features of a given physical system to bring the equations of motion into a particularly simple form. Most researchers rely on a random choice for the generalized speeds [2].

The proposed method of this paper shows that Kane's method can be modified and the optimal choice of the set of generalized speeds leads to simpler equations of motion. An illustrative application is solved using the modified Kane's method. 


\section{FORMULATIONS}

Kane's method reduces the procedures required to formulate the equations of motion and yields simple equations. To show that, a rigid multibody system is considered. The linear velocities of that system are described in two cases. First, description by means of body coordinates. Second, description by means of joint coordinates.

\subsection{Formulation by Means of Body Coordinates (Case I)}

A floating base mechanical open chain system of five-rigid bodies is shown in Fig. 1. The bodies are connected to each other by either a prismatic (P) or revolute (R) joint. When $\boldsymbol{r}_{i}$ is the position vector to any point on body $\mathrm{i}$. Hence, the linear velocities could be as follows

$$
\begin{aligned}
& \dot{r}_{1}=\dot{r}_{1} \\
& \dot{r}_{2}=\dot{r}_{1}-\widetilde{d}_{21} \omega_{1}+\dot{q}_{2} u_{2} \\
& \dot{r}_{3}=\dot{r}_{1}-\widetilde{d}_{31} \omega_{1}+\dot{q}_{2} u_{2} \\
& \dot{r}_{4}=\dot{r}_{1}-\widetilde{d}_{41} \omega_{1}+\dot{q}_{2} u_{2}-\dot{q}_{3} \widetilde{d}_{43} u_{3}-\underline{\dot{q}_{4} \widetilde{c}_{4} u_{4}} \\
& \dot{r}_{5}=\dot{r}_{1}-\widetilde{d}_{51} \omega_{1}+\dot{q}_{2} u_{2}-\dot{q}_{3} \widetilde{d}_{53} u_{3}-\dot{q}_{4} \widetilde{d}_{54} u_{4}+\dot{q}_{5} u_{5}-\underline{\dot{q}_{4} \widetilde{c}_{4} u_{4}}
\end{aligned}
$$

Where $\dot{q}_{i}$ and $\dot{r}_{i}$ are the joint velocity and the linear velocity of the $\mathrm{i}^{\text {th }}$ body, $\widetilde{d}_{i j}$ and $\widetilde{c}_{i}$ are $(3 \times 3)$ skew symmetric matrices such that $d_{i j} \times u_{i}=\widetilde{d}_{i j} u_{i}$ and $c_{i} \times u_{i}=\widetilde{c}_{i} u_{i}, d_{i j}$ describes a vector between a point on body $i$ to a point on body $\mathrm{j}$ (only $d_{31}$ and $d_{51}$ are shown in the figure for demonstration), the vector $c_{i}$ is between the joint (i-1) and the center of mass of body $i$, and $\boldsymbol{u}_{\mathrm{i}}$ is a unit vector passes through the $i^{\text {th }}$ joint axis.

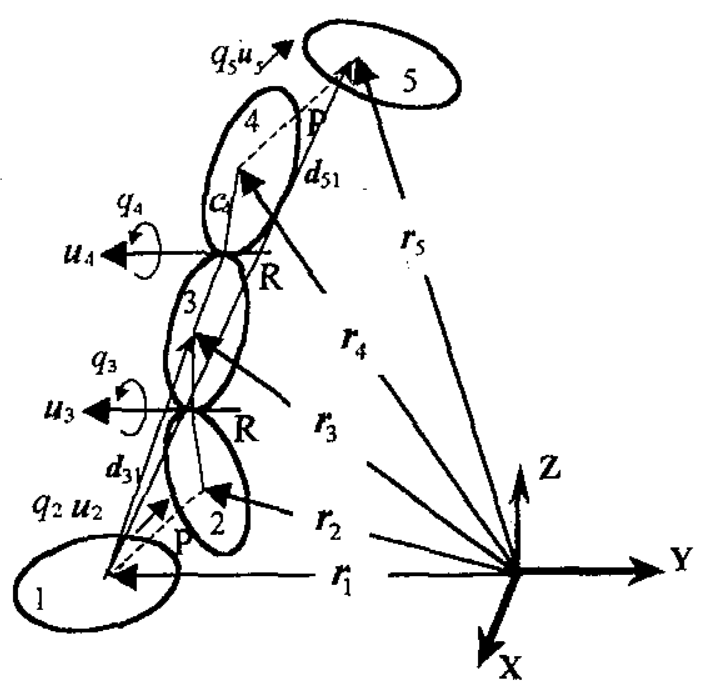

Fig. 1. System configuration for body coordinates 


\subsection{Formulation by Means of Joint Coordinates (Case I)}

In this case, the position vector $\boldsymbol{r}_{i}$ is pointed toward the joints as shown in Fig.

2. The Linear velocities can be written as

$$
\begin{aligned}
& \dot{r}_{1}=\dot{r}_{1} \\
& \dot{r}_{2}=\dot{r}_{1}-\widetilde{d}_{21} \omega_{1}+\dot{q}_{2} u_{2} \\
& \dot{r}_{3}=\dot{r}_{1}-\widetilde{d}_{31} \omega_{1}+\dot{q}_{2} u_{2} \\
& \dot{r}_{4}=\dot{r}_{1}-\widetilde{d}_{41} \omega_{1}+\dot{q}_{2} u_{2}-\dot{q}_{3} \tilde{d}_{43} u_{3} \\
& \dot{r}_{5}=\dot{r}_{1}-\widetilde{d}_{51} \omega_{1}+\dot{q}_{2} u_{2}-\dot{q}_{3} \widetilde{d}_{53} u_{3}-\dot{q}_{4} \widetilde{d}_{54} u_{4}+\dot{q}_{5} u_{5}
\end{aligned}
$$

Comparing the equations of the above two cases, it is obvious that the underlined-redundant terms in Case (I) are eliminated. This reduces the terms needed to formulate the equations of motion. As a result, the case of joint coordinates is more efficient and recommended.

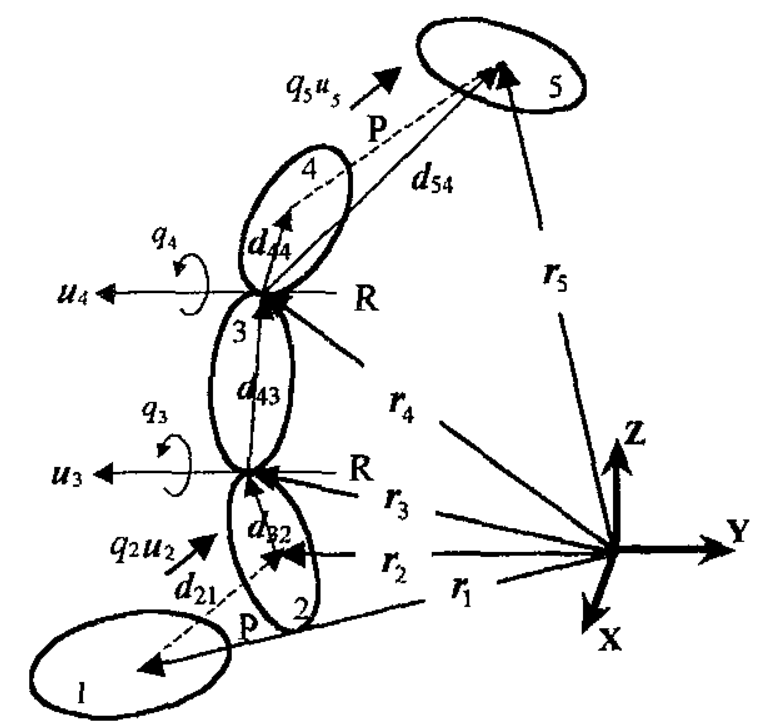

Fig. 2. System configuration for joint coordinates

\section{MODIFIED KANE'S METHOD}

The proposed method is demonstrated by considering the five-rigid bodies system shown in Fig. 2 as a case study. First, the generalized speeds are randomly selected. They could be chosen as a set of angular velocities and linear velocities or simply a set of independent joint velocities.

$$
s_{1}=\dot{r}_{1}, \quad s_{2}=\omega_{1}, \quad s_{3}=\dot{q}_{2}, \quad s_{4}=\dot{q}_{3}, \quad s_{5}=\dot{q}_{4} \quad \text { and } \quad s_{6}=\dot{q}_{5}
$$

Hence, the angular velocities could be written as 


$$
\begin{aligned}
& \omega_{1}=\omega_{1} \\
& \omega_{2}=\omega_{1} \\
& \omega_{3}=\omega_{1}+\dot{q}_{3} u_{3} \\
& \omega_{4}=\omega_{1}+\dot{q}_{3} u_{3}+\dot{q}_{4} u_{4} \\
& \omega_{5}=\omega_{1}+\dot{q}_{3} u_{3}+\dot{q}_{4} u_{4}
\end{aligned}
$$

They can be also rewritten in terms of generalized speeds as

$$
\begin{aligned}
& \omega_{1}=s_{2} \\
& \omega_{2}=s_{2} \\
& \omega_{3}=s_{2}+s_{4} u_{3} \\
& \omega_{4}=s_{2}+s_{4} u_{3}+s_{5} u_{4} \\
& \omega_{5}=s_{2}+s_{4} u_{3}+s_{5} u_{4}
\end{aligned}
$$

Moreover, the linear velocities, which are presented by Eq. 2, can be also rewritten in terms of generalized speeds as

$$
\begin{aligned}
& \dot{r}_{1}=s_{1} \\
& \dot{r}_{2}=s_{1}-\widetilde{d}_{21} s_{2}+s_{3} u_{2} \\
& \dot{r}_{3}=s_{1}-\widetilde{d}_{31} s_{2}+s_{3} u_{2} \\
& \dot{r}_{4}=s_{1}-\widetilde{d}_{41} s_{2}+s_{3} u_{2}-s_{4} \widetilde{d}_{43} u_{3} \\
& \dot{r}_{5}=s_{1}-\widetilde{d}_{51} s_{2}+s_{3} u_{2}-s_{4} \widetilde{d}_{53} u_{3}-s_{5} \tilde{d}_{54} u_{4}+s_{6} u_{5}
\end{aligned}
$$

The angular and linear velocities can be arranged in a matrix form as follows

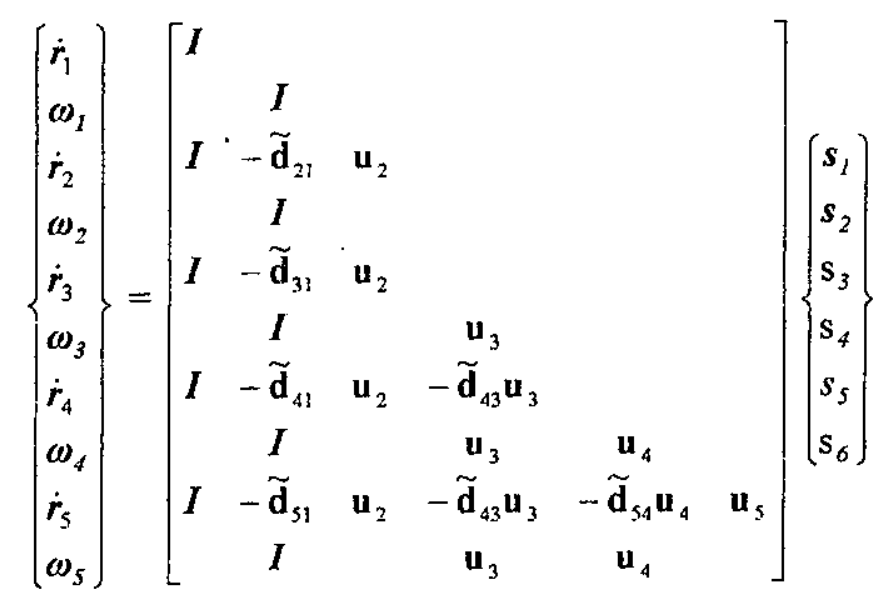

where, $I$ is a $(3 \times 3)$ identity matrix.

A so-called "Column Reduction Process (CRP)" [4] is applied to reduce the coefficient matrix for the system of equations presented in Eq. (7). This method is developed on the basis of linear algebra. The process is carried out by subtracting a column from other multiplied columns to get as many zero 
elements as possible. The reduction process starts from the last column toward the first column (i.e., from right to left). For instance, if the right-hand term of the equation system presented in Eq. (7) can be represented as $A \boldsymbol{s}$, after certain operations by using the CRP, this term is converted to $B s^{*}$. The superscripted $s^{*}$ is the new objective set of the modified generalized speeds (i.e. optimal generalized speeds). Note that $\boldsymbol{A s} \equiv \boldsymbol{B} \boldsymbol{s}^{*}$. The new reduced form is

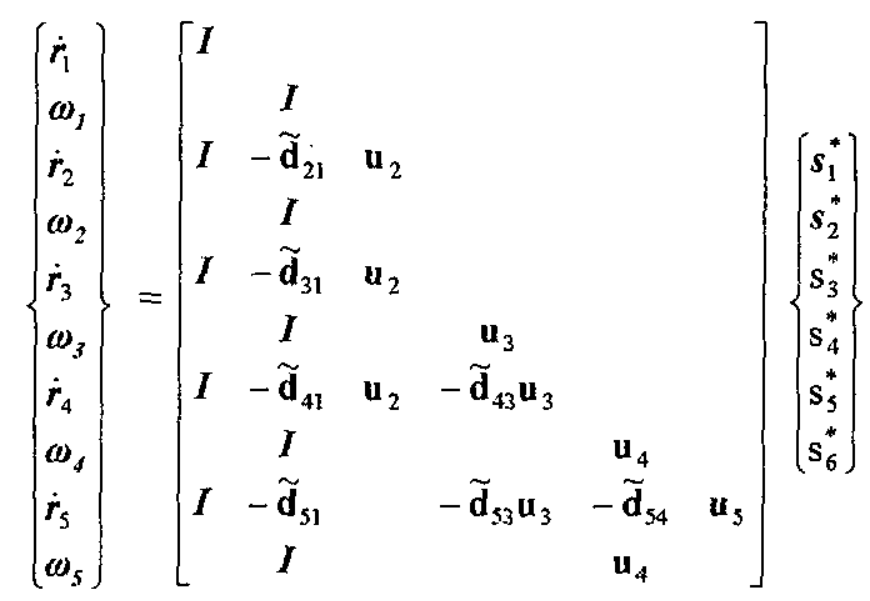

In the obtained reduced form, the elements $(8,4),(9,3)$ and $(10,4)$ are eliminated. The optimal set of generalized speeds $s^{*}$ can be expressed in terms of the initial generalized speeds as linear combinations as follows,

$$
s_{1}^{*}=s_{1}, \quad s_{2}^{*} \equiv s_{2}, \quad s_{3}^{*}=s_{3}, \quad s_{4}^{*}=s_{4}, \quad s_{5}^{*}=s_{4}+s_{5} \quad \text { and } \quad s_{6}^{*}=s_{3}+s_{6}
$$

Finally, the angular velocities in terms of the optimal generalized speeds are

$$
\begin{aligned}
& \omega_{1}=s_{2}^{*} \\
& \omega_{2}=s_{2}^{*} \\
& \omega_{3}=s_{2}^{*}+s_{4}^{*} u_{4} \\
& \omega_{4}=s_{2}^{*}+s_{5}^{*} u_{4} \\
& \omega_{5}=\omega_{4}
\end{aligned}
$$

Likewise, the linear velocities in terms of the optimal set of the generalized speeds are

$$
\begin{aligned}
& \dot{r}_{1}=s_{1}^{*} \\
& \dot{r}_{2}=s_{1}^{*}-\widetilde{d}_{21} s_{2}^{*}+\mathrm{s}_{3}^{*} u_{2} \\
& \dot{r}_{3}=s_{1}^{*}-\tilde{d}_{31} s_{2}^{*}+s_{3}^{*} u_{2} \\
& \dot{r}_{4}=s_{1}^{*}-\tilde{d}_{41} s_{2}^{*}+s_{3}^{*} u_{2}-s_{4}^{*} \tilde{d}_{43} u_{3} \\
& \dot{r}_{5}=s_{1}^{*}-\tilde{d}_{51} s_{2}^{*}+s_{6}^{*} u_{5}-s_{4}^{*} \tilde{d}_{43} u_{3}-s_{5}^{*} \tilde{d}_{54} u_{4}
\end{aligned}
$$


The deduced angular and linear velocities in terms of the optimal set of the generalized speeds are considered as a basic kinematics requirement for deriving Kane's equations of motion. Since they reduce the terms needed to formulate those equations and hence the time required for implementing the problem.

\section{CONCLUSIONS}

A modified computational approach for Kane's equations is presented in this paper. The velocity transformation matrix of partial angular velocities and partial linear velocities is constructed. The optimal set of the combined generalized velocities can be determined according to the developed procedure based on Kane's method. The deduced generalized speeds give fewer terms of the generated equations of motion. Comparative analyses between two cases of body coordinate formulation and joint coordinate formulation is achieved. The comparison reveals that the joint coordinate formulation is more efficient and recommended. The proposed modified Kane's method can be applied to any general multibody system.

\section{REFERENCES}

[1] Huston, R.L., "Multibody Dynamics Formulations Via Kane's Equations," AlAA Dyn Spec Conf, Washington, DC, pp. 424-430 (1990).

[2] Samak, S.M., "Dynamic Model Error Analysis of Robot Manipulators," Ph.D. Dissertation, University of Michigan, Ann Arbor, Michigan, MI (1990).

[3] Blajer, W., "Useful Matrix of Kane's Equations," Mechanics Research Communications Vol. 17 (1990), No. 5, pp. 311-318.

[4] Maher, B.M., "Some Developed Analytic Methods For Spatial Rigid Multibody Dynamics," Ph.D. thesis, Cairo university, EGYPT (1996).

[5] Lesser, M., "A Geometrical Interpretation of Kane's Equations," Proceeding of the Royal Society, London, Series A. Mathematical and Physical Sciences, 436, No.1896, pp. 69-87 (1992).

[6] Murphy, B.R., Maruyama, T. and Uchiyama, T., "Survey of Kane's Dynamics and it's use in Multibody Dynamics," Proc. of the 28th SICE Annual Conference, Vol. II, pp. $1183-7$ (1989).

[7] Singer, N.C. and Seering, W.P., "Two Extensions to Kane's Method for Simplifying Equation Derivation," J. of the Astronautical Sciences, Vol. 41 (1993), No. 3, pp. 283-298.

[8] Song, P., Ma, X. and Zou, Z., "On the Nature of Kane's Equations from a Geometrical Viewpoint in Configuration Space," J. of Harbin Institute of Technology, Harbin, Gongye, Daxue, Xuebao, (1991), No. 2, pp. 119-123.

[9] Tran, D.M., "Presentation of Kane's Method for Formulating Equations of Motion," Recherche Aerospatiale, No. 3, pp. 1-21 (1991).

[10] Hussain, M.A., Nobel, B. and Mckee, M., "Multibody Dynamics and Kane's Equations," Symbolic Computations and their Impact on Mechanics, Pressure Vessels and Piping Division, Vol. 205, pp. 265-274, New York (1990). 
[11] Huston, R.L., "Multibody Dynamics," Butterworth-Heinemann (1990).

[12] Kane, T.R. and Levinson, D.A., "Dynamics' ,Theory and Applications," McGraw Hill (1985).

[13] Kane, T.R., "Dynamics," Holt, Rinehart, and Winston, New York (1968).

[14] Huston, R.L., Passerello, C.E. and Harlow, M.W., "Dynamics of MulirigidBody Systems," J. of Applied Mechanics, Vol. 45 (1978), pp. 889-894. 


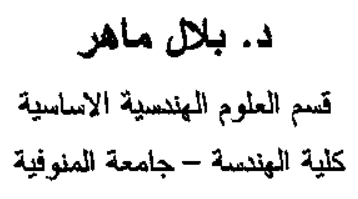

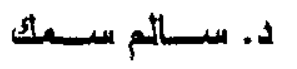

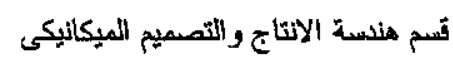 \\ كلية الهنسية - جامعة المنوفية ولئية
}

ملنص البحث

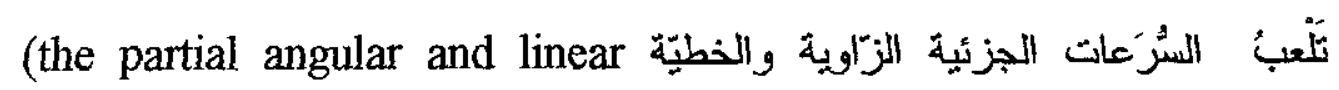

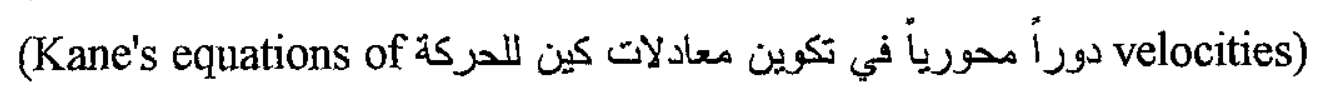
.motion)

يتعرض هذا البحث إلى أن طريقة كين تعمل على تخفيض الخطوات المطلوبة لتكوين معادلات الحركة وذلك عندما توصف السرعات الخطية عن طريق محاور المفاصل بدلا من محاور الأجسام.

كما يهدف إلى تقديم طريقة حسابية مطورة لُتبسيًَّ وَحَل معادلات كين لحركة منظومة ذات أجسام جاسئة متعددة (rigid multibody system)، ويتحقق ذلك

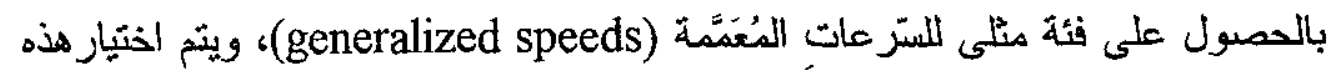

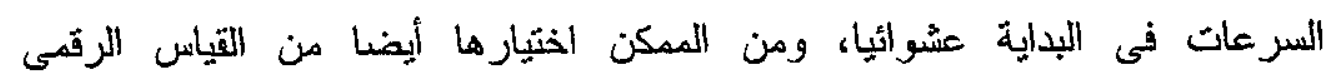

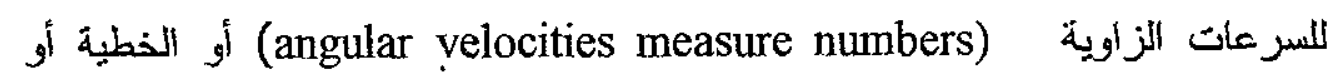
بيساطة من sعدلات متغيرات المفاصل (joint variable rates)، ثم يتم بعد ذللك تكوين مصفوفة تحويل السرعات الجزئية، والتى يتم تخفبضها بانستخام طريقة الأعمدة

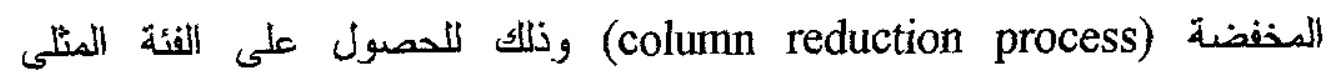

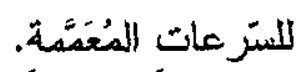

تم اختيار نطبيق لتوضبح الطريقة المقترحة عبارة عن نظام ميكنيكى مكون من خمسة أجسام جاسئة، الأجسام منصلة ببعضها بواسطة مفصل دورانى (revolute) أو مفصل من لئل إسنطالى (prismatic).

يؤول هذا البحث إلى أن إختيار أفضل لمجموعة السرعات المعممة فى طريقة كين يؤدى إلى معادلات حركة أبسط. 